\title{
Ribotyping as a molecular biological technique for studying diversity in Shigella isolates - A Review
}

\author{
Partha Pal \\ Department of Zoology, Scottish Church College, \\ 1 \& 3 Urquhart Square, Kolkata - 700006, India \\ Phone: 91-33-2350-3862 \\ E-mail address: parthapal_iicb@yahoo.co.in
}

\begin{abstract}
Diarrhoea in developing countries is caused by an increasingly long list of bacterial, viral, and parasitic pathogens with rotavirus, Enterotoxigenic Escherichia coli, Campylobacter, Shigella, and Salmonella heading the list. Using methods to detect most of the known enteropathogens, one or more enteropathogen(s) is isolated in two-thirds of diarrhoeal illnesses in the developing world. Deoxyribonucleic acid probes have proved very useful in detecting pathogens such as enterotoxigenic (ETEC), enteroinvasive (EIEC), enteropathogenic E. coli (EPEC), and Shigella but have not yet proved to be particularly rapid or less expensive. Molecular biology has proved useful in epidemiological studies as a means of strain identification and detection of genome diversity. Since the introduction of ribonucleic acid gene restriction patterns as taxonomic tools in 1986, ribotyping has become an established method for systematics, epidemiological, ecological population and genome diversity studies of microorganisms including Shigella. The technological development culminated in the automation of ribotyping which allowed for high-throughput applications. PCR ribotyping has proved being a highly discriminatory, flexible, robust and cost-efficient routine technique which makes inter-laboratory comparison and build of ribotype databases possible, too. The aim of the present review is to determine the present status of ribotyping technique in detecting the diversity in Shigella isolates.
\end{abstract}

Keywords: Bacterial systematics; Enteropathogens; Ribotyping; Shigella; Taxonomy

\section{INTRODUCTION}

Shigella has been identified as one of the most important agent of diarrhea by World Health Organization (WHO, 2005). According to Silva et al. (Silva et al., 2008), shigellosis is currently an important health problem around the world, occurring predominantly in children younger than five years old, mainly in developing countries. Shigellosis is caused by Shigella spp., including $S$. dysenteriae, S. flexneri, S. boydii and S. sonnei (Kuo et al., 2008). Shigella is generally transmitted by contaminated water, uncooked food, and by contact with infected individuals (Navia and Gascón, 2005). Humans and few primates are the only known reservoirs of Shigella (Ribeiro, 2000; WHO, 2005), and transmission among humans are common. Shigella has been characterized by diverse methods, including antibiotic resistance and genotyping methods in Brazil (Penatti et al., 2007) and in other countries as Chile (Fullá et al., 2005), Iran (Ribeiro, 2000), and Spain (Flórez et al., 2005). However, due to the low discrimination power of the antimicrobial resistance typing, DNA based methods has been 
recommended. Among them, PCR-ribotyping has been applied with success because it is rapid to perform, presents relatively low cost and also has been used to type enteric pathogens such as Salmonella (Jamil et al., 2007; Nastasi and Mammina, 1995; Oliveira et al., 2007). Ribotyping represents a molecular subtyping method that has found widespread application, including for subtyping of food borne pathogens and of microorganisms important for fermentation and food spoilage. In this method presence of multiple copies of rRNA genes in a bacterium is mainly utilized. For ribotyping, first restriction digestion of chromosomal DNA of the test organism is carried out followed by Southern hybridization with an rRNA probe in order to generate DNA banding patterns, which allow subtype differentiation of bacterial isolates beyond the species and subspecies levels.

Although, serological identification is crucial and rapid in diagnosis of Shigella infections, but some critical aspects must be considered: (i) its success depends on the quality of the antisera used (Carlin and Lindberg, 1983; Carlin et al., 1986), (ii) none of the commercially available antisera recognizes $S$. dysenteriae serotypes 13 to 15 or provisional serotypes; (iii) numerous intra- and interspecific cross-reactions have been reported, requiring multiple absorption steps during antiserum production (Ansaruzzaman et al., 1995; Ewing, 1986; Gross et al., 1989) and (iv) the transition from smooth to rough forms, which do not produce $\mathrm{O}$ antigens, makes such isolates untypeable by serotyping. To overcome these troublesome constraints, ribotyping may be of great help. In an earlier report (Matsushita et al., 1997), an MluI ribotyping scheme correlated overall with serotyping. As discussed above, the ribotyping procedure identifies and compares restriction fragments of the chromosomal rDNA region, which includes DNA carrying rRNA genes grouped as operons and flanking DNA regions, after hybridization with rRNA or rDNA probes. rDNA probes are usually developed from a recombinant plasmid in which rrn (rRNA) DNA has been inserted, or in some cases commercially available rDNA probes are used (Talukder et al., 2002).

The ribotyping technique has been utilized in the identification of a group of Shigellalike isolates, which were described, to be linked with Shigella boydii type 20 (Grimont et al., 2007). Ribotyping of $S$. dysenteriae type 2 strains in Bangladesh showed an identical pattern of all the strains that suggested the clonal nature of the emerging strains (Talukder et al., 2006a). PCR-ribotyping has been used to characterize the Shigella isolates responsible for foodborne outbreaks occurred in the Southern Brazil (Paula et al., 2010). However, the purpose of the present review is to asses the present scenario of the ribotyping technique in the field of genome diversity of Shigella species.

\section{MOLECULAR GENETIC BASIS OF RIBOTYPING}

Typically, each ribosomal operon consists of the three genes encoding the structural rRNA molecules, $16 \mathrm{~S}, 23 \mathrm{~S}$, and $5 \mathrm{~S}$, cotranscribed as a polycistronic operon. Among bacterial species, the average lengths of the structural rRNA genes are 1,522 bp, 2,971 bp, and $120 \mathrm{bp}$, for $16 \mathrm{~S}, 23 \mathrm{~S}$, and $5 \mathrm{~S}$, respectively. The copy numbers, overall ribosomal operon sizes, nucleotide se-quences, and secondary structures of the three rRNA genes are highly conserved within a bacterial species (Maidak et al., 1997) due to their fundamental role in polypeptide synthesis (Woese, 1996). Because the 16S rRNA gene is the most conserved of the three Rrna genes, 16S rRNA gene sequencing has been established as the "gold standard" for identification and taxonomic classification of bacterial species (Kolbert and Persing, 1999; Pace et al., 1986; Woese, 1987). Knowledge of intraspecies conservation of the 16S rRNA gene sequence (Fox et al., 1980) and basic 16S-23S-5S ribosomal operon structure (Doolittle and Pace, 1971) led Grimont and Grimont (Grimont and Grimont, 1986) to the first insights into its usefulness in developing ribotyping for bacterial classification. Based on 
these fundamental insights, the molecular genetic basis of conventional ribotyping was further elucidated.

The conventional ribotyping is based on restriction endonuclease cleavage of total genomic DNA followed by electrophoretic separation, Southern blot transfer (Southern, 1975), and hybridization of transferred DNA fragments with a radiolabeled ribosomal operon probe. Following autoradiography, only those bands containing a portion of the ribosomal operon are visualized. The number of fragments generated by ribotyping is a reflection of the multiplicity of rRNA operons present in a bacterial species. Copy numbers of rRNA operons have been found to range from 1 (e.g., for Chlamydia trachomatis) to 15 (e.g., for Photobacterium profundum) (Klappenbach et al., 2001).

The use of a single restriction endonuclease with a conserved cleavage site in the $16 \mathrm{~S}$ and $23 \mathrm{~S}$ rRNA genes would enable detection of DNA sequence polymorphisms in immediately adjacent upstream and downstream genes flanking each ribosomal operon following hybridization of the electrophoresed chromosomal digest with a labeled rRNA gene operon probe. It then follows that the total number of RFLP bands so detected would be equal to twice the number of ribosomal operons, with an additional fragment(s) reflecting the 16S-23S internal spacer. Well before the first genomic sequence became available in 1995, the linear Escherichia coli linkage map (Bachmann, 1990) revealed that chromosomal genes immediately flanking $(\sim 50 \mathrm{~kb})$ the seven ribosomal operons of this species consist primarily of evolutionarily neutral housekeeping genes the same category of genes used for phylogenic analysis by multilocus enzyme electrophoresis (MLEE) (Selander et al., 1986) and more recently by multilocus sequence typing (MLST) (Maiden et al., 1998). This perspective therefore implied that RFLPs generated by ribotyping could be used to characterize the evolutionary genetic relatedness of independent isolates (Bouchet et al., 2008).

\section{PCR RIBOTYPING}

PCR ribotyping was developed by Kostman et al. (Kostman et al., 1995; 1992) and Gurtler et al. (Gurtler and Barrie, 1995; Gurtler and Stanisich, 1996) in the 1990s as a response in part to the need in the clinical microbiology laboratory setting for expeditious epidemiological discrimination among pathogenic microorganisms without the use of probes, thus making the analysis more widely applicable. Using primers complementary to the $3^{\prime}$ end of the 16S rRNA gene and the $5^{\prime}$ end of the $23 \mathrm{~S}$ rRNA gene, PCR ribotyping reveals length heterogeneity of the PCR-amplified internal spacer regions (ISR) (Gurtler and Barrie, 1995; Kostman et al., 1995).

Although developed for epidemiological analysis and for discrimination of pathogens, PCR ribotyping proved not to be universally applicable (Cartwright, 1995). One species with which this methodology has found some success is Clostridium difficile, having a total of 11 ribosomal operons, with differing tRNAs and ISR lengths found among ribosomal operons of the same organism (Sebaihia etal., 2006) (GenBank accession number AM180355). An analysis of 45 isolates of $C$. difficile from which the intervening sequence (IVS) had been sequenced did not reveal striking sequence length diversity. 


\section{1. PCR Ribotyping followed by restriction endonuclease subtyping}

In addition to length variation, many species demonstrate high degrees of sequence variability among multiple copies of the ISR (Gurtler and Stanisich, 1996). Such variability is due, in part, to the fact that intergenic regions often encode one or two tRNAs (Anton et al., 1998; Christensen et al., 1999). As well, certain organisms (e.g., E. coli) possess multiple alleles of the rRNA gene cluster, with considerable interallelic variation occurring in the lengths and sequences of the ISRs both at the level of operons in the same genome and between operons within a species. In an attempt to further subtype isolates for which PCR ribotyping was nondiscriminatory, Ryley et al. (Ryley et al., 1995) and Shreve et al. (Shreve et al.1997) performed PCR amplification of ISRs, followed by restriction endonuclease digestion. While additional discriminatory power was found in some cases, the method proved to be inherently limited, typically generating only two to four bands.

\section{2. Long PCR Ribotyping}

As a means to enhance the differentiating capacity of PCR ribotyping followed by restriction digestion Smith-Vaughan et al. (Smith-Vaughan et al., 1995) developed long PCR ribotyping. This technique is based on PCR amplification of the entire 16S-23S-5S ribosomal operon $(\sim 5.5 \mathrm{~kb})$ followed by restriction endonuclease digestion (Smith-Vaughan et al., 1995). This method should be more discriminatory than $16 \mathrm{~S}$ sequencing alone in that it covers the more highly variable ISR yet possesses the epidemiologic advantages of the species-specific conservation of $16 \mathrm{~S}$ and, to a lesser degree, 23S rRNA genes (Bouchet et al., 2008)

\section{RIBOTYPING IN Shigella ISOLATES}

DNA hybridization studies revealed more than $73 \%$ DNA relatedness between Shigella (with the exception of certain $S$. boydii isolates) and E. coli K-12. In view of this fact, these organisms have been placed in the same genomic group (Coimbra et al., 2001).

Ribotyping has several advantages over other molecular typing methods. Because the ribosomal genes are located on the chromosome, they are not readily lost. In addition, the rDNA patterns are not sensitive to antibiotic pressure, and they are not dependent on susceptibility to phages or production of colicins. The high degree of conservation in the ribosomal genes allows the use of a single universal probe to subtype all prokaryotes. Most bacteria contain multiple copies of the ribosomal operons; therefore, an acceptable number of fragments (3 to 15) that hybridize with the probe are generated. Hybridization of SalIrestricted DNA from E. coli with $16 \mathrm{~S}$ and $23 \mathrm{~S}$ rRNA genes produced 15 fragments: 14 fragments representing the left and right halves of each of the seven operons and the common internal fragment from each operon. With respect to the number of SalI fragments carrying sequences homologous to rRNA, the restriction patterns observed for $S$. sonnei were similar to those observed in E. coli (Hinojosa-Ahumada et al., 1991). These findings suggested that, like E. coli, $S$. sonnei also carries seven rRNA operons. This seems likely since both organisms are so closely related that they are phylogenetically indistinguishable by DNA reassociation analysis (Brenner et al., 1973).

The close relatedness of $S$. sonnei strains was also observed by Ochman et al. (Ochman et al., 1983) using multilocus enzyme analysis, and Brenner et al. (Brenner et al., 1973), using DNA reassociation tests. The discriminating capacity of this method can be increased by using multiple enzymes. With $S a l$ I restriction enzyme $S$. sonnei isolates were divided into six different groups only. However, it can be distinguished into nine groups using multiple 
enzymes (Hinojosa-Ahumada et al., 1991). Yogev et al. (Yogev et al., 1988) made similar observations about the increased discrimination obtained by using more than one restriction enzyme to ribotype Mycoplasmas.

The ribotyping results for isolates from the Texas (July 1986 and September 1986) and Minnesota outbreaks compared favorably with their colicin typing results. All isolates from the July 1986 Texas outbreak, which were rDNA pattern 2b, were colicin type 9, and all isolates from the September 1986 Texas outbreak, which were rDNA pattern 2a, were colicin type 7 (Hinojosa-Ahumada et al., 1991).

The advantage of ribotyping over colicin typing is that all strains are typeable by ribotyping, while a significant number of isolates may not be typeable by colicin typing. Morris and Wells (Morris and Wells, 1974) reported that $40 \%$ of strains from 33 different outbreaks of $S$. sonnei infection in the United States were untypeable by the colicin typing method. With ribotyping, the rDNA patterns were reproducible, and no differences between patterns were observed for rough and smooth variants of the same strain.

Although some researchers have obtained variable results with ribotyping, the technique has been indicated to be useful for epidemiological studies of $S$. sonnei (Mendoza et al., 1996). Hinojosa-Ahmuda and colleagues have found six ribotypes when $100 \mathrm{~S}$. sonnei were studied using SalI restriction enzyme (Hinojosa-Ahumada et al., 1991). Nastasi and colleagues have also found 13 ribotypes by examining $432 \mathrm{~S}$. sonnei isolates (Nastasi et al., 1993). Ranjbar et al. (Ranjbar et al., 2008) observed a single ribotype pattern among the $S$. sonnei isolates collected in Tehran.

Ribotyping technique proved that rDNA restriction pattern analysis is a valuable tool in epidemiological research on S. boydii (Bratoeva et al., 1992; Nastasi et al., 1990). In a recent study all $S$. boydii strains were categorized into two patterns only. Moreover, all but one isolates, belonged to ribotype I (Ranjbar et al., 2008). However, this finding is similar to recent reports from other developing countries, such as Bangladesh (Talukder et al., 2006b). Hybridization of HindIII-digested chromosomal DNA of representative strains of $S$. dysenteriae type 2 isolates in Bangladesh with the 16S rDNA probe revealed a total of six fragments ranging in size of approximately 5-15 kb. DNA fragments were arranged in a similar fashion in all the strains suggesting their identity in ribotyping pattern. Acording to Talukder et al. (Talukder et al., 2006 a) this data showed a high degree of conformance of the isolates by biochemical measures and ribotyping.

In a recent study conducted in Brazil using PCR-ribotyping banding patterns of ten isolates that could not be identified to species level, listed as Shigella spp, were found to be similar to those presented by $S$. sonnei $(\mathrm{n}=2)$ and $S$. flexneri $(\mathrm{n}=8)$, suggesting that the ten isolates belonged to these two species. Serology experiments confirmed these results. The study indicated that the several Shigella strains involved in different Shigellosis outbreaks present the same PCR-ribotyping banding pattern and also the same resistance profile, suggesting that closely related strains may have been the causative agent of the outbreaks (Paula et al., 2010). According to Navia and Gascón (Navia and Gascón, 2005), most often the cases or outbreaks of shigellosis occur due to the clonally propagation of one or a few strains.

It should be noted that PCR-ribotyping resulted in lower number of banding patterns that did the antibiotic resistance testing. Even though antimicrobial resistance in microorganisms could be mediated by plasmids or other transmissible DNA elements, not modifying chromosomal DNA, other molecular typing methods are required to assure the clonal relationship of the Shigella strains. PCR-ribotyping was able to correctly differentiate species of Shigella, demonstrating to be useful for foodborne outbreaks investigation (Paula et al., 2010). 


\section{DISCUSSION AND CONCLUSION}

Earlier studies reveal that the ribosomal operon flanks in bacteria are composed principally of housekeeping genes and that genetic variation in these genes is primarily responsible for ribotype polymorphisms. The evolutionary neutrality of housekeeping genes constitutes a major factor in the interpretation of ribotype RFLPs. Elucidation of the basis of ribotyping at this molecular genetic level has since allowed investigators to confidently use this technique to study bacterial population genetics and species diversity (Bouchet et al., 2008). PFGE and ribotyping have been considered to be highly discriminatory in subtyping strains of Shigella and other enteric pathogens (Talukder et al., 2006 a). The ability to type all strains by ribotyping makes it an attractive technique to complement traditional methods for investigating outbreaks of Shigella sonnei infection. For characterizing strains collected over extended periods of time, ribotyping may provide more dependable discrimination than plasmid profile analysis or antibiotic susceptibility testing since the genes encoding rRNA are chromosomally located and are not readily lost (Hinojosa-Ahumada et al., 1991). Several Shigella strains demonstrated similar PCR ribotyping banding patterns and also antibiotic resistance profile, suggesting that closely related strains were responsible for the studied foodborne shigellosis outbreaks occurred in the State of Rio Grande do Sul in Brazil (Paula et al., 2010).

In the present review, it was concluded that modern researches are utilizing various innovative approaches based on molecular biological techniques for detection of pathogenic virulent strains that are responsible for human diseases. The conventional ribotyping methods are now being modified for rapid and precise detection of pathogenic isolates like Shigella and other enteric pathogens. The emergence of new antibiotic resistant Shigella isolates having genomic heterogeneity with epidemic potential is a major challenge of the current era. The need for an accurate, rapid and cost effective technique based on the principle of ribotyping will help scientist to fight against this emerging problem of mankind. This present review will help researchers for understanding the present status of the ribotyping technique in the detection of Shigella isolates and also the genomic diversity of these pathogenic bacteria.

\section{References}

[1] Ansaruzzaman M., Kibriya A.K.M.G., Rahman A., Neogi P.K.B., Faruque A.S.G., Rowe B., Albert M.J., J Clin Microbiol 33 (1995) 1423-1425.

[2] Anton A. I., Martinez-Murcia A.J., Rodriguez-Valera F., J Mol Evol 47 (1998) 62-72.

[3] Bachmann B.J., Microbiol. Rev. 54 (1990) 130-197.

[4] Bouchet V., Huot H., Goldstein R., Clin Microbiol Rev 21 (2008) 262-273.

[5] Bratoeva M.P., John J.F., Barg N.L., J Clin Microbiol 30 (1992) 1428-1431.

[6] Brenner D.J., Fanning G.R., Miklos G.V., Steigerwalt A.G., Int J Syst Bacteriol 23 (1973) 1-7.

[7] Carlin N.I.A., Lindberg A.A., J Clin Microbiol 18 (1983) 1183-1189. 
[8] Carlin, N.I.A., Wehler T., Lindberg A.A., Infect Immun 53 (1986) 103-109.

[9] Cartwright C., J Infect Dis 172 (1995) 1638-1639.

[10] Christensen H., Jorgensen K., Olsen J.E., Microbiology 145 (1999) 99105.

[11] Coimbra R.S. atr al., J Clin Microbiol 39 (2001) 618-621.

[12] Doolittle W.F., Pace N.R., Proc Natl Acad Sci USA 68 (1971) 17861790.

[13] Ewing W.H., Elsevier Publishing Co 4th ed. (1986) 135-172.

[14] Flórez A.J., Pérez-Roth E., González-Linares S., Méndez-Álvarez S., Int Microbiol 8 (2005) 133-136

[15] Fox, G.E. et al., Science 209 (1980) 457-463.

[16] Fullá N., Prado V., Durán C., Lagos R., Levine M.M., Am J Trop Med Hyg 72(6) (2005) 851-854.

[17] Grimont F., Grimont P.A., Ann Inst Pasteur Microbiol 137B (1986) 165-175.

[18] Grimont F. et al., J Med Microbiol 56 (2007) 749-754.

[19] Gross R.J., Thomas L.V., Cheasty T., Rowe B., Lindberg A.A., J Clin Microbiol 27 (1989) 829-831.

[20] Gurtler V., Barrie H.D., Microbiology 141 (1995) 1255-1265.

[21] Gurtler V., Stanisich V.A., Microbiology142 (1996) 3-16.

[22] Hinojosa-Ahumada M., J Clin Microbiol. 29 (1991) 2380-2384.

[23] Jamil M. et al., Pak J Med Sci 23(2) (2007) 233-237.

[24] Klappenbach J.A., Saxman P.R., Cole J.R., Schmidt T.M., Nucleic Acids Res 29 (2001) 181-184.

[25] Kolbert C.P., Persing D.H., Curr Opin Microbiol 2 (1999) 299-305.

[26] Kostman J.R., Alden M.B., Mair M., Edlind T.D., LiPuma J.J., Stull T.L., J Infect Dis 171 (1995) 204-208.

[27] Kostman J.R., Edlind T.D., LiPuma J.J., Stull T.L., J Clin Microbiol 30 (1992) 2084-2087.

[28] Kuo C.Y. et al., J. Microbiol Immunol Infect 41 (2008) 107-111.

[29] Maidak B.L., Olsen G.J., Larsen N., Overbeek R., McCaughey M.J., Woese C.R., Nucleic Acids Res 25 (1997) 109-111.

[30] Maiden M.C. et al., Proc Natl Acad Sci USA 95 (1998) 3140-3145.

[31] Matsushita S., Noguchi Y., Yanagawa Y., Kobayashi K., Nakaya H., Igarashi H., Kudoh Y., Kansenshogaku Zasshi 71 (1997) 412-416.

[32] Mendoza M.C, Martin M.C., Gonzalez-Hevia M.A., Epidemiol Infect 116 (1996) 127-35. 
[33] Morris G.K., Wells J.G., Appl Microbiol 27 (1974) 312-316.

[34] Nastasi A., Mammina C., Res Microbiol 146(1) (1995) 99-106.

[35] Nastasi A., Pignato S., Mammina C., Giammanco G., Epidemiol Infect 110 (1993) 23-30.

[36] Nastasi A., Villafrate M.R., Mammina C., Pontello M., Ricci M., Res Microbiol 141 (1990) 1163-1172.

[37] Navia M.M., and Gascón V.J., Infect Genet Evol 5 (2005) 349-353.

[38] Ochman H., Whittam T.S., Caugant D.A., Selander R.K., J Gen Microbiol 129 (1983) 2715-2726.

[39] Oliveira F.A. de, Frazzon A.P., Brandelli A., Tondo E.C., J Infect Develop Country 1 (2007) 170-176.

[40] Pace N.R., Olsen G.J., Woese C.R., Cell 45 (1986) 325-326.

[41] Paula C.M.D., Geimba M.P, do Amaral P.H., Tondo E.C., Braz J Microbiol 40 (2010) 966-977.

[42] Penatti M.P.A., Hollanda L.M., Nakazato G., Campos T.A., Lancellotti M., Angellini M., Brocchi M., Rocha M.M.M., Silveira W.D. da., Braz J Med Biol Res (2007).

[43] Ranjbar R., Soltan Dallal M.M., Talebi M., Pourshafie M.R., J Health Popul Nutr 26 (2008) 426-430.

[44] Ribeiro R.V. (2000): http://www.ccs.saude.gov.br/visa/publicacoes/arquivos/bol7.pdf

[45] Ryley H.C., Millar-Jones L., Paull A., Weeks J., J Med Microbiol 43 (1995) 436-441.

[46] Sebaihia M. et al., Nat Genet 38 (2006) 779-786.

[47] Selander R.K., Caugant D.A., Ochman H., Musser J.M., Gilmour M.N., Whittam T.S., Appl Environ Microbiol 51 (1986) 873-884.

[48] Shreve M.R., Johnson S.J., Milla C.E., Wielinski C.L., Regelmann W.E., Am J Respir Crit Care Med 155 (1997) 984-989.

[49] Silva T., Nogueira P.A., Magalhães G.F., Grava A.F., Silva L.H.P. da, Orlandi P.P., Mem Inst Oswaldo Cruz 103(7) (2008) 731-733.

[50] Smith-Vaughan H.C., Sriprakash K.S., Mathews J.D., Kemp D.J., J Clin Microbiol 33 (1995) 1192-1195.

[51] Southern E.M., J Mol Biol 98 (1975) 503-517.

[52] Talukder K.A., Islam M.A., Dutta D.K, Hassan F., Safa A., Nair G.B., Sack D.A., J Clin Microbiol 40 (2002) 2490-2497.

[53] Talukder, K.A., Khajanchi B. K., Islam M.A., Dutta D.K., Islam Z., Khan S.I., Nair G.B., Sack D.A., Epidemiol Infect 134 (2006 a) 1249-1256. 
[54] Talukder K.A. et al., J Med Microbiol 55 (2006 b) 1257-1263.

[55] WHO (2005),

http://www.who.int/vaccine_research/documents/Guidelines_Shigellosis.pdf.

[56] Woese C.R. (1996). CRC Press, Boca Raton, FL.

[57] Woese C.R., Microbiol Rev 51 (1987) 221-271.

[58] Yogev D., Halachmi D., Kenny G.E., Razin S., J Clin Microbiol 26 (1988) 1198-1201. 